DOI: $10.12731 /$ wsd-2018-1-38-51

УДК 598.2(470.21)

\title{
ОСОБЕННОСТИ ГНЕЗДОСТРОЕНИЯ И ХАРАКТЕРИСТИКА ГНЕЗД БОЛЫШОЙ СИНИЦЫ (PARUS MAJOR L.) И ОБЫКНОВЕННОЙ ГОРИХВОСТКИ (РНOENICURUS PHOENICURUS L.) В УРБАНИЗИРОВАННОМ ЛАНДШАФТЕ Г. МОНЧЕГОРСКА
}

\author{
Корякина Т.Н.
}

В работе проанализирован состав и характеристика гнезд дуплогнездяшуихся птиц в черте г. Мончегорска и прилегающих территорий: больиой синицы $(n=35)$ и обыкновенной горихвостки $(n=17)$ за пятилетний период. Определень основные параметры гнезд для большой синицьы: высота

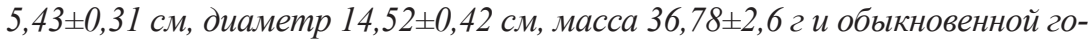

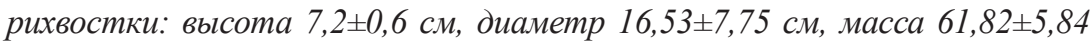
2. Средняя дата начала гнездостроения у большой синицьь при первой попытке гнездования 09 мая 1,27 ( lim $_{\text {min }}=24$ апреля, lim $_{\max }=23$ мая; $n=27$ ), при второй попьтке гнездования 24 июня 1 , 79 (lim $_{\min }=18$ июня, $\lim _{\max }=11$ июля;

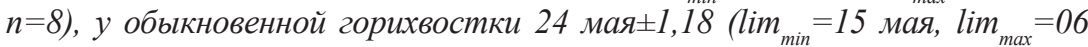
июня; $n=17)$. Преобладающей древесной породой для заселения синичников и постройки гнезд у дуплогнездящихся птии является береза субарктическая (Betula subarctica Orlova). Наибольшее число гнезд большой синицы $(28,5 \%)$ приходится на гнезда с четырьмя компонентами; гнезда, состоящчие из 2 и 3 компонентов, составляют, соответственно, 8,5\% и 22,9\% от общеег числа гнезд. В гнездах большой синиць количество компонентов колеблется от 2 до 5, в среднем 4,37士0,28, основныли из которых являются зеленылй мох и собачья шерсть. Преобладающее количество гнезд обыкновенной горихвостки состоит из семи компонентов (29,5\%), на гнезда, состоящие из четырех, пяти и иести компонентов, приходится по 17,6\%; количество компонентов находится в диапазоне от 3 до 10, в среднем 6士0,46. Cамьми распространенными компонентами гнезда обыкновенной горихвостки являются: побеги трав, листья, кора и труха. Данные компоненты являются традиционными природными материалами для гнезд перечисленных 
видов птиц. В качестве специфических антропогенных компонентов, для постройки гнезд птицами используются: полиэтилен, бумага (картон), шерстяные нитки, мешковина, вата, синтепон. Процент встречаемости антропогенных материалов составляет $34,3 \%$ для гнезд большой синицы и $52,9 \%$ для гнезд обыкновенной горихвостки.

Ключевые слова: гнездо; строительный материал; природные и антропогенные компоненты; большая синица (Parus таjor L.); обыкновенная горихвостка (Phoenicurus phoenicurus L.).

\section{FEATURES GASTOSTOMY AND CHARACTERISTICS OF NESTS OF THE GREAT TIT (PARUS MAJOR L.) AND THE COMMON REDSTART (PHOENICURUS PHOENICURUS L.) IN THE URBANIZED LANDSCAPE OF THE CITY OF MONCHEGORSK}

\section{Koryakina T.N.}

The author made an analysis the composition and characteristics of nests of hole-nesting birds within the city of Monchegorsk and neighbouring areas: the great tit $(n=35)$ and the common redstart $(n=17)$ over a five-year period. The main parameters of the nests for the great tit are as follows: the height of $5.43 \pm 0.31 \mathrm{~cm}$, diameter of $14.52 \pm 0.42 \mathrm{~cm}$, weight $36.78 \pm 2.6 \mathrm{~g}$ and the common redstart: height of $7.2 \pm 0.6 \mathrm{~cm}$, diameter of $16.53 \pm 7.75 \mathrm{~cm}$, weight $61.82 \pm 5.84 \mathrm{~g}$. the Average starting date of the construction of the nest great tit at the first attempt of nesting 09 May $\pm 1,27\left(\right.$ (im $_{\min }=$ April 24, lim $_{\max }=$ May 23; $\left.n=27\right)$, a second attempt of nesting 24 June \pm 1.79 (lim $\left._{\min }=J u n e ~ 18, \lim _{\max }=J u l 11 ; n=8\right)$, the common redstart May $24 \pm 1.18\left(\lim _{\min }=\right.$ May 15, lim $_{\max }=$ June 06; $\left.n=17\right)$. The predominant tree species for settlement nest-boxes and built nests of hole-nesting birds is the subarctic birch (Betula subarctica Orlova). The highest number of nests of the great tit (28.5\%) are in the nest with the four components; the nest, consisting of 2 and 3 components are, respectively, $8.5 \%$ and $22.9 \%$ of the total number of nests. In the nests of the great tit the number of components ranges from 2 to 5, an average of $4.37 \pm 0.28$, the main ones are green moss and dog wool. The overwhelming number of nests of the common redstart consists of seven components (29.5\%), nests, containing four, five and six components, accounting for 17.6 percent; the number of components is in the range from 3 to 10, averaging $6 \pm 0.46$. The most typical components of the common redstart nests are grass sprouts, leaves, bark and trash. Shoots of grasses, 
leaves, bark and trash - based nest of the common redstart. These components are the traditional natural materials for nests listed bird species. As a specific anthropogenic components used by birds to build their nests, used: polyethylene, paper (cardboard), wool yarn, burlap, cotton, polyester. The percentage of occurrence of anthropogenic materials $34.3 \%$ for nests of the great tit and $52.9 \%$ for nests of the common redstart.

Keywords: nest; nest materials; natural and anthropogenic components; great tit (Parus major L.); common redstart (Phoenicurus phoenicurus L.).

\section{Введение}

Большая синица и обыкновенная горихвостка - широко распространенные виды. Большая синица - оседлый, обычный и многочисленный вид городских ландшафтов Мурманской области. Обыкновенная горихвостка типичная лесная птица региона, активно осваивающая городские ландшафты.

Дуплогнездники - достаточно удобный модельный вид, на котором можно изучать различные аспекты гнездовой биологии птиц [1]. Экологические особенности представителей группы позволяют им быть универсальными индикаторами среды. Развешивание синичников в городской черте является благоприятным условием для формирования контрольных площадок для изучения влияния различных факторов на птиц на разных стадиях размножения и собирать достаточно большой первичный материал [2].

К основным факторам успешной реализации экологической ниши для дуплогнездящихся птиц относятся: особенности пространственной структуры города, наличие корма и мест для гнездования. Они формируют население птиц-дуплогнездников в черте города. Гнездовая жизнь птиц включает четыре основных этапа: строительство гнезда, откладку яиц, вылупление и вылет птенцов. Комплексное изучение гнездовой биологии птиц включает изучение строения гнезда и гнездового материала как важного этапа периода размножения.

Цели данной работы: 1. Дать характеристику гнезд дуплогнездящихся птиц (масса, высота, диаметр); 2. изучить состав строительного материала гнезд большой синицы и обыкновенной горихвостки в условиях урбанизированной среды города Мончегорска и прилегающих территорий.

\section{Материалы и методы}

На территории города Мончегорска с 2010 г. ведется систематическая работа по изучению биологии размножения птиц-дуплогнездников. Для этого в разных районах города установлены искусственные гнездовья для 
привлечения дуплогнездящихся птиц в городскую черту.

Материал был собран в 2010-2014 гг. в черте г. Мончегорска, который находится в Мурманской области и расположен в западной гористой части Кольского полуострова на западном берегу оз. Имандра при впадении в него р. Монча севернее Полярного круга ( $67^{\circ} 55^{\prime}$ с.ш., $32^{\circ} 57^{\prime}$ в.Д.). Общее количество многоквартирных домов в городе Мончегорске составляет 331 (общая площадь - 1 207,6 м или 23,6 м на одного жителя). 97\% от общего количества жилья размещено в каменных двух- девятиэтажных многоквартирных домах, 3\% - в двухэтажных деревянных. К числу ветхого фонда можно отнести часть деревянной малоэтажной застройки в районе Монча и кварталы капитального жилого фонда средней этажности в центральной части города. Жилой фонд характеризуется высоким уровнем инженерного оборудования - $100 \%$ жилья обеспечено водопроводом, канализацией, теплоснабжением, горячим водоснабжением [3]. Градообразующее предприятие города - комбинат «Североникель», производящий медно-никелевую продукцию, начавший работу в 1935 г. С 1999 года - структурное подразделение ОАО «Кольская горно-металлургическая компания».

Растительный покров г. Мончегорска представляет собой сочетание участков:

1) сохранившихся остатков естественных фитоценозов;

2) искусственно культивируемых насаждений (скверы, дворы, картофельные огороды и т.п.);

3) антропогенных растительных сообществ, самостоятельно возникающих на участках уничтоженной дикой растительности (пустыри, прибрежные насыпи, карьеры и т.п.).

Сохранившиеся массивы старовозрастных лесов представлены сосновоелово-березовыми кустарничково-зеленомошными и лишайниковыми лесами. По берегам водоемов представлены заболоченные редкостойные багульниковые и сфагновые сосняки, заболоченные разнотравные березняки с ивой и ольхой, осоковые и кустарничково-сфагновые болота. На влажных склонах встречаются густейшие заросли высокоствольных ивняков с примесью сосны, ели и березы [4].

Основными породами деревьев, которые представлены в зеленых массивах города и где были развешены искусственные гнездовья, являются: береза, ель, сосна.

За пять лет исследований проанализировано 35 гнезд большой синицы и 17 гнезд обыкновенной горихвостки. Для большой синицы исследованы гнезда первой $(n=27)$ и второй $(n=8)$ попыток гнездования за сезон. 
Для определения размера, массы и строительного материала использовали заселенные гнезда после вылета птенцов, собранные в городской черте Мончегорска. Материалы, используемые птицами для постройки гнезд, анализировали отдельно.

Определение систематической принадлежности растительных компонентов гнезд производилось с разной степенью точности в зависимости от сохранности материалов. При невозможности детального определения указывали лишь его тип (например, стебли злаковых). Латинские названия приведены в соответствии с аннотированными списками сосудистых растений и позвоночных животных Лапландского заповедника [5; 6].

Воздушно-сухие гнезда (т.е. гнезда, высушенные в течение 5-7 дней в сухом помещении до постоянной массы) и отдельные компоненты гнезд взвешивали на аналитических весах с точностью до 0,01 г. Размеры гнезд определяли линейкой с точностью до 0,1 см, высоту гнезд - штангенциркулем с точностью до 0,1 см [7].

Постоянное движение птенцов в гнезде приводит к быстрому разрушению гнезда и к моменту вылета гнездовая постройка представляет собой более или менее ровную площадку у синицы или бесформенную массу у горихвостки. Поэтому не у всех гнезд удалось в полном объеме снять параметры, особенно у обыкновенной горихвостки. Для этого вида в основном представлены данные для целого гнезда (масса и состав компонентов гнезда).

\section{Результаты и обсуждение}

За пять лет наблюдений на городской территории отмечено гнездование четырех видов птиц-дуплогнездников, которые относятся к Отряду Воробьинообразные Passeriformes: большая синица (Parus major L.), обыкновенная горихвостка (Phoenicurus phoenicurus L.), сероголовая гаичка (Parus cinctus Bodd), мухоловка-пеструшка (Ficedula hypoleuca Pall.). Основными видами являются большая синица и обыкновенная горихвостка. Они выбирают искусственные гнездовья на участках с повышенной антропогенной нагрузкой, включая жилые или общественные помещения, многолюдные места и участки рядом с автодорогами. Выбор мест гнездования определяют разные параметры растительного сообщества, которые включают видовой состав древостоя, его пространственную структуру, степень затененности и влажности. Эти факторы определяют кормовую базу для выкармливания птенцов, температурный режим гнезда, его защищенность от неблагоприятных погодных условий [8]. Наиболее охотно 
птицы заселяли синичники в сохранившихся спелых хвойно-лиственных остаточных естественных фитоценозах со значительной примесью или преобладанием березы субарктической в черте города и вдоль дороги по пр. Ленина, где высажены деревья. Если горихвостка предпочитает окраины города, то большая синица равномерно занимает искусственные гнездовья как в центре города (вблизи жилых помещений, вдоль автодорог), так и по окраинам. Как и в других частях ареала, прослеживается характерное для большой синицы предпочтение древостоев с преобладанием лиственных пород [9; 10].

Преобладающей древесной породой для заселения синичников и постройки гнезд, как у большой синицы, так и у горихвостки является береза субарктическая (Betula subarctica Orlova). Менее активно птицы заселяют искусственные гнездовья, расположенные на сосне Фриза (Pinus friesiana) и осине (Populus tremula L.). Единичные случаи гнездования зафиксированы на иве (Salix sp.) и ели сибирской (Picea obovata) (рис. 1).

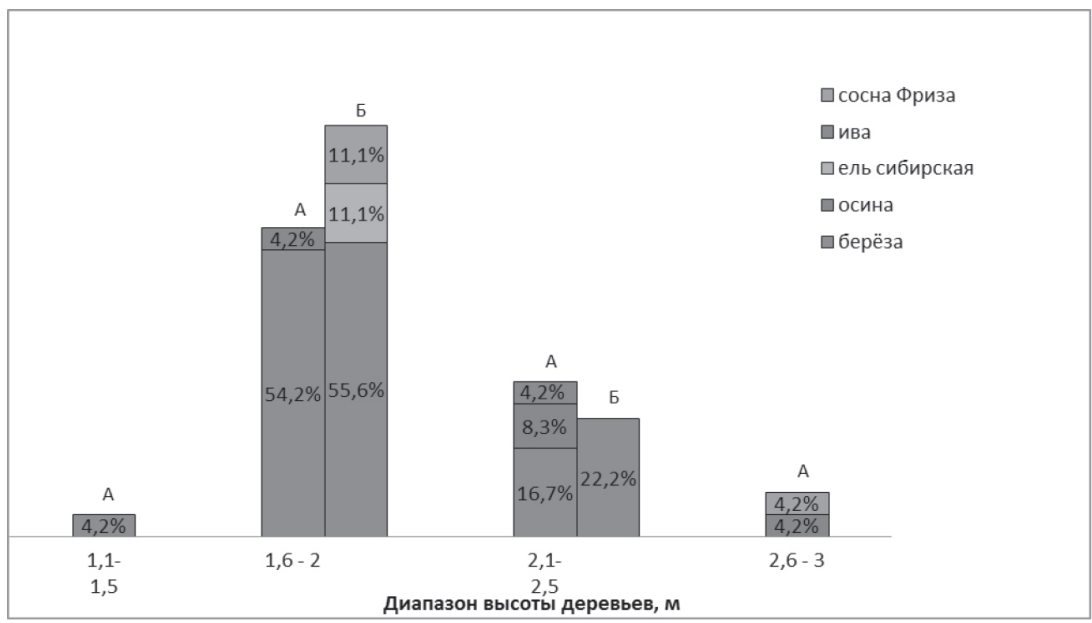

Рис. 1. Распределение гнезд большой синицы $(A)$ и обыкновенной горихвостки (Б) по породам и высоте деревьев в г. Мончегорске и на прилегающих территориях The distribution of nests of the great tit (A) and common redstart (B) the species and height of trees in Monchegorsk and the surrounding areas

Гнездо обыкновенной горихвостки после изъятия из гнезда - это бесформенная масса листьев с другими компонентами. Выстилка представлена стеблями злаковых и перьями птицы. Лоток смещен к одному из краев гнезда 
и сооружен из побегов трав и выстлан перьями. Кладка во время инкубации находится в лотке и при отсутствии птицы в гнезде, прикрыта перьями. В каркасе существенную долю от состава гнезда составляют кора деревьев и труха - именно за счет этих компонентов гнезда горихвостки, как правило, объемнее и тяжелее, чем гнезда большой синицы (табл. 1, табл. 2).

Преобладающее количество гнезд обыкновенной горихвостки состоит из семи компонентов $(29,5 \%)$, на гнезда, состоящие из четырех, пяти и шести компонентов, приходится по 17,6\%; количество компонентов находится в диапазоне от 3 до 10, в среднем $6 \pm 0,46$.

Таблица 1.

Размеры гнезд большой синицы и обыкновенной горихвостки в г. Мончегорске

The size of the nests of the great tit and common redstart in Monchegorsk

\begin{tabular}{|c|c|c|c|c|c|c|}
\hline \multirow{2}{*}{ Параметр } & \multicolumn{3}{|c|}{ Большая синица } & \multicolumn{3}{c|}{ Обыкновенная } \\
& $\frac{\mathrm{X} \pm m, \mathrm{~cm}}{\mathrm{Lim}}$ & $\sigma$ & $C V, \%$ & $\frac{\mathrm{X} \pm m, \mathrm{~cm}}{\mathrm{Lim}}$ & $\sigma$ & $C V, \%$ \\
\hline Диаметр гнезда & $\frac{14,52 \pm 0,42}{10,4-18,3}$ & 2,35 & 16,18 & $\frac{16,53 \pm 1,75}{10,1-20,4}$ & 3,93 & 23,71 \\
\hline Диаметр лотка & $\frac{6,26 \pm 0,29}{4,47-10,4}$ & 1,35 & 21,57 & $\frac{7,81 \pm 0,88}{5,2-12}$ & 2,15 & 27,53 \\
\hline Высота гнезда & $\frac{5,43 \pm 0,31}{1,9-8,55}$ & 1,78 & 32,78 & $\frac{7,2 \pm 0,6}{4,12-10,1}$ & 1,8 & 24,86 \\
\hline Глубина лотка & $\frac{3,84 \pm 0,31}{1,8-6,1}$ & 1,37 & 35,68 & $\frac{3,85 \pm 0,34}{2,4-4,9}$ & 0,9 & 23,38 \\
\hline
\end{tabular}

Примечание. $X$ - среднее арифметическое признака, $m$ - ошибка средней, $\mathrm{lim}$ - минимальное и максимальное значение признака, $\sigma$ - среднее квадратичное отклонение, $\mathrm{CV}$ - коэффициент вариации.

Таблииа 2 .

Масса гнезд большой синицы и обыкновенной горихвостки в г. Мончегорске The mass of the nests of the great tit and common redstart in Monchegorsk

\begin{tabular}{|c|c|c|c|c|c|c|}
\hline \multirow{2}{*}{ Параметр } & \multicolumn{3}{|c|}{ Большая синица } & \multicolumn{3}{|c|}{ Обыкновенная горихвостка } \\
\cline { 2 - 7 } & $\frac{\mathrm{X} \pm m, \Gamma}{\mathrm{Lim}}$ & $\sigma$ & $C V, \%$ & $\frac{\mathrm{X} \pm m, \Gamma}{\mathrm{Lim}}$ & $\sigma$ & $C V, \%$ \\
\hline Масса каркаса & $\frac{21,5 \pm 2,1}{8,9-39,22}$ & 7,71 & 35,86 & ----- & ----- & ----- \\
\hline Масса лотка & $\frac{12,35 \pm 1,3}{5,95-21,64}$ & 4,87 & 39,43 & ----- & ----- & ----- \\
\hline Масса гнезда & $\frac{36,78 \pm 2,6}{6,89-725,56}$ & 14,26 & 38,78 & $\frac{61,82 \pm 5,84}{18,06-119,45}$ & 23,34 & 37,75 \\
\hline
\end{tabular}


Наибольшее число гнезд большой синицы (28,5\%) приходится на гнезда с четырьмя компонентами; гнезда, состоящие из 2 и 3 компонентов, составляют, соответственно, $8,5 \%$ и $22,9 \%$ от общего числа гнезд (рис. 2). В гнездах большой синицы количество компонентов колеблется от 2 до 5, в

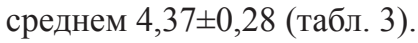

Таблицуа 3.

Количество компонентов в гнездах большой синицы и обыкновенной горихвостки в г. Мончегорске The number of components in the nests of the great tit and common redstart in Monchegorsk

\begin{tabular}{|c|c|c|c|c|c|c|}
\hline \multirow{2}{*}{ Параметр } & \multicolumn{2}{|c|}{ Большая синица } & \multicolumn{3}{c|}{$\begin{array}{c}\text { Обыкновенная } \\
\text { горихвостка }\end{array}$} \\
\cline { 2 - 7 } & $\frac{\mathrm{X} \pm m}{\mathrm{Lim}}$ & $\sigma$ & $C V, \%$ & $\frac{\mathrm{X} \pm m}{\mathrm{Lim}}$ & $\sigma$ & $C V, \%$ \\
\hline Каркас & $\frac{2,69 \pm 0,21}{1-6}$ & 1,21 & 44,98 & ----- & ----- & ----- \\
\hline Выстилка & $\frac{1,69 \pm 0,12}{1-4}$ & 0,68 & 40,24 & ---- & ----- & ----- \\
\hline Гнездо целиком & $\frac{4,37 \pm 0,28}{2-9}$ & 1,61 & 36,84 & $\frac{6 \pm 0,46}{3-10}$ & 1,79 & 29,83 \\
\hline
\end{tabular}

Гнездо большой синицы представляет собой прямоугольный «спрессованный» брикет или гомогенную массу; лоток находится в центре гнезда. В городе выстилка обычно представлена собачьей шерстью с небольшими вкраплениями антропогенного материала: ниток и полиэтилена. В естественных условиях обитания в выстилке используется шерсть диких животных (полевки, лемминга, лося, зайца и др.). В гнездах синиц зеленый мох, который является основой каркаса гнезда, почти всегда остается главным строительным материалом, потому что он является хорошим теплоизолятором и в то же время является достаточно мягким для последующего изменения формы гнезда [11]. Во время инкубации яиц (при вылете синицы из гнезда) кладка чаще всего прикрыта шерстью и находится в середине массы мало теплопроводного пружинящего зеленого мха и шерсти. Такой способ сохранения ненасиженных яиц позволяет синицам начинать гнездование раньше большинства других птиц-дуплогнездников [12]. По нашим наблюдениям средняя дата начала гнездостроения у большой синицы при первой попытке гнездования 09 мая $\pm 1,27\left(\lim _{\min }=24\right.$ апреля, $\lim _{\max }=23$ мая; $\left.n=27\right)$, при второй попытке гнездования 24 июня $\pm 1,79$ ( $\lim _{\min }=18$ июня, $\lim _{\max }=11$ июля; $\left.n=8\right)$, у обыкновенной горихвостки 24 мая $\pm 1,18\left(\lim _{\min }=15\right.$ мая, $\lim _{\max }=06$ июня; $n=17)$. Период гнездостроения у большой синицы составляет 14 дней, у 
обыкновенной горихвостки 8 дней. Сроки начала гнездостроения обуславливаются весенними температурами, особенностями миграции (большая синица - оседлый вид в регионе, обыкновенная горихвостка - перелетный вид, улетающий на зимовку в центральную Африку и на юг Аравийского полуострова), эволюционными приспособлениями в выборе компонентов.

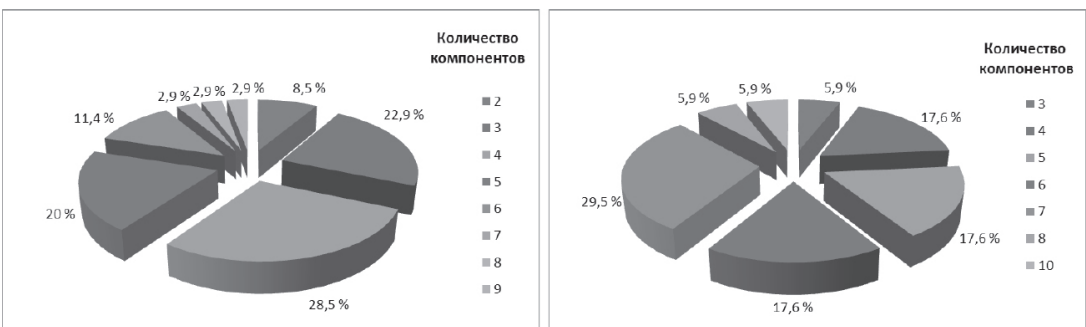

Рис. 2. Распределение гнезд по количеству компонентов (\%) большой синицы (слева) и обыкновенной горихвостки (справа)

The distribution of nests by number of items (\%) great tit (left) and common redstart (right)

Таблииа 4.

Встречаемость (\%) разных типов материалов в гнёздах большой синицы и обыкновенной горихвостки в г. Мончегорске, \% от общего числа гнёзд The frequency of occurrence $(\%)$ of different types of materials in the nests of the great tit and common redstart in Monchegorsk, $\%$ of the total number of nests

\begin{tabular}{|c|c|c|c|c|c|c|}
\hline \multirow{2}{*}{ Параметр } & \multicolumn{3}{|c|}{ Большая синица } & \multicolumn{3}{c|}{ Обыкновенная горихвостка } \\
\cline { 2 - 7 } & гнездо & каркас & выстилка & гнездо & каркас & выстилка \\
\hline $\begin{array}{c}\text { Ветви деревьев } \\
\text { и кустарников }\end{array}$ & 40 & 40 & --- & 17,6 & 17,6 & --- \\
\hline Кора, древесина & 2,8 & 2,8 & --- & 82,4 & 82,4 & --- \\
\hline Труха & ---- & ---- & ---- & 41,2 & 41,2 & --- \\
\hline Корни & 5,7 & 5,7 & ---- & 41,2 & 41,2 & --- \\
\hline Листья & 31,4 & 29 & 2,4 & 100 & 93 & 7 \\
\hline Стебли злаковых & 65,7 & 61 & 4,7 & 100 & 95,3 & 4,7 \\
\hline Хвощи & 37,1 & 35,5 & 1,6 & 17,6 & 17,6 & --- \\
\hline Хвоя & 22,9 & 22,9 & --- & 17,6 & 17,6 & --- \\
\hline Плоды, соцветия & --- & ---- & --- & 5,9 & 5,9 & --- \\
\hline Мох & 100 & 91 & 9 & 58,2 & 58,2 & --- \\
\hline Перья & 9,1 & ---- & 9,1 & 100 & 8 & 92 \\
\hline Шерсть & 100 & 11 & 89 & 5,9 & 5,9 & --- \\
\hline Шкурки грызунов & 8,6 & 8,6 & ---- & 23,5 & 23,5 & --- \\
\hline Антропогенные & 34,3 & 24,7 & 9,6 & 52,9 & 52,9 & --- \\
\hline материалы & 5,7 & 5,7 & ---- & 5,9 & 5,9 & --- \\
\hline Лишайник & 5,7 & & &
\end{tabular}


Из табл. 4 следует, что основными компонентами в гнездах большой синицы являются зеленый мох (Плеурозий или плевроциум Шребера Pleurozium schreberi (Brid.)Mitt (=Hylocomiumschreberi (Brid.) DeNot.)), coбачья шерсть, стебли злаковых, ветви деревьев и кустарников, хвощи: хвощ полевой (Equisetum arvense L.) и хвощ луговой (Equisetum pratense Ehrh.). Стебли злаковых представлены несколькими видами, одним из которых является полевица северная (Agrostis borealis C.Hartm.), ветви деревьев и кустарников, используемые птицами при строительстве гнезд, - это береза субарктическая (Betula subarctica Orlova), ель сибирская (Picea obovata), вороника или водяника обоеполая (Empetrum hermaphroditum Hagerup). У большой синицы к единичным компонентам можно отнести лишайник и хвою.

В гнездах обыкновенной горихвостки основной строительный материал распределен следующим образом: стебли злаковых, листья, труха, кора, древесина. Основу строительного материала гнезд горихвостки составляют прошлогодние сухие части растений и прошлогодняя опавшая листва. В основном, в гнезде были определены листья березы субарктической (Betula subarctica Orlova), ивы (Salix sp.) и рябины Городкова (Sorbus gorodkovii Pojark. (S. glabrata (Wimm. et Grab.)). В гнездах в незначительном количестве встречается земля, которая попадает вместе с растительным строительным материалом.

Компоненты, преобладающие в гнездах птиц, встречаются в каждом гнезде: у большой синицы это зеленый мох и шерсть, у горихвостки - перья, листья, стебли злаковых. Исходя из этого, можно сделать вывод, что именно эти компоненты являются основными для постройки гнезда.

Многие из воробьиных птиц используют в строительстве своих гнезд шкурки погибших в природе мышевидных грызунов. Следует отметить, что шкурки грызунов в искусственных гнездовьях на исследуемой территории встречаются только в 2012 г. за весь период исследования. Это объясняется тем, что накануне, в 2011 г. был отмечен очередной максимум их численности [13]. В гнездах птиц были обнаружены шкурки норвежского лемминга (Lemmus lemmus L.), лесного лемминга (Myopus schisticolor L.) и красно-серой полевки (Clethrionomys rufocanus S.) на городской периферии.

Оба вида птиц используют антропогенные компоненты в строительстве гнезд. К специфическим антропогенным компонентам относятся: полиэтилен, бумага (картон), шерстяные нитки, мешковина, вата, синтепон. В одном гнезде горихвостки была обнаружена полиэтиленовая веревка длиной 55 см. Процент встречаемости антропогенных материалов составляет $34,3 \%$ для гнезд большой синицы и 52,9\% для гнезд обыкновенной горихвостки. 


\section{Заключение}

Высокий адаптивный потенциал дуплогнездящихся птиц наиболее выраженно проявляется на фазе гнездостроения. Характер постройки и компонентов гнезда специфичен для каждого вида и определяется, в основном, образом жизни птицы. Гнезда горихвостки больше, тяжелее и разнообразнее по количеству компонентов, чем гнезда большой синицы. Птицы-дуплогнездники в городе Мончегорске используют при строительстве гнезд традиционные природные материалы: рыхлые, поддающиеся уплотнению компоненты, и плоские детали, легко сдвигающиеся относительно друг друга. В гнездах большой синицы основным строительным материалом являются зеленый мох, который используется для строительства каркаса, и шерсть для выстилки лотка. Каркас гнезда обыкновенной горихвостки состоит из листьев, стеблей злаковых, ветвей, коры и трухи, лоток выстлан перьями птицы. Так же проведенные наблюдения показали, что в городской черте птицы помимо традиционных природных компонентов, активно используют материалы антропогенного происхождения в выстилке и в каркасе, что является адаптацией к урбанизированному ландшафту и меняющимся условиям среды.

\section{Список литературы}

1. Скрыпникова Е.Б. Особенности экологии большой синицы как фонового вида орнитокомплексов г. Воронежа // Современные проблемы науки и образования. 2011. №5. https://www.science-education.ru/ru/article/view?id=4821

2. Лебедева Н.В. Птицы-дуплогнёздники как модельные объекты биоиндикации // Птицы-дуплогнёздники как модельные объекты в решении проблем популяционной экологии и эволюции: материалы международной конференции. М.: Т-во научных изданий КМК, 2014. С. 167-170.

3. Инвестиционный паспорт города Мончегорска, 2013 [Электронный реcypc]. http://minec.gov-murman.ru/files/invest_monch.pdf.

4. Мониторинг состояния природной среды Лапландского государственного природного биосферного заповедника, а также территории, прилегающей к ОАО комбинат «Североникель», включая г. Мончегорск и его окрестности (пятый этап): отчет по договору с Кольской Горно-Металлургической компанией № Д-1089 / Рук. и отв. исполнитель В.Ш. Баркан. Мончегорск, 2002. 134 с. Архив Лапландского заповедника.

5. Берлина Н.Г. Сосудистые растения Лапландского заповедника (аннотированный список видов) // Флора и фауна заповедников. Вып. 64. М., 1997. 58 с.

6. Катаев Г.Д. Млекопитающие. Фауна Лапландского заповедника // Флора и фауна заповедников. Вып. 63. М., 1997. С. 39-44. 
7. Шубина Ю.Э., Федерякина И.А., Лыков Е.Л. Размеры, масса и строительный материал гнёзд черного дрозда (Turdus Merula (Aves) в Липецкой и Калининградской областях // Бюл. Моск. о-ва испытателей природы. Отд. биол. 2011. Т. 116. Вып. 6. С. 48-53.

8. Молоканова Ю.П. Особенности экологии гнездования пеночек (Phylloscops) в Московской области // Электронный журнал «Вестник МГОУ». 2013. № 1. C. 1-22.

9. Артемьев А.В. Популяционная экология большой синицы Parus major в таёжных лесах Карелии. Ч. 1. Структура населения и особенности гнездования // Учёные записки Петрозаводского государственного университета. 2008. № 2 (92). C. 31-43.

10. Зимин В.Б. Материалы по гнездованию большой синицы (Parus Major L.) в Карелии // Фауна и экология птиц и млекопитающих таёжного Северо-Запада СССР. Петрозаводск, 1978. С. 17-31.

11. Благосклонов К.Н. Гнездование и привлечение птиц в сады и парки. М.: Изд-во МГУ, 1991. $251 \mathrm{c.}$

12. Бианки В.В., Шутова Е.В. К экологии большой синицы Parus major в Мурманской области // Русский орнитологический журнал. 2011. Том 20. Экспресс-выпуск 628. С. 186-195.

13. Катаев Г.Д. Мониторинговые исследования фауны мелких млекопитающих Micromammalia на Кольском полуострове (Лапландский заповедник) // Экологические проблемы северных регионов и пути их решения: материалы V Всероссийской научн. конф. с междунар. участием 23-27 июня 2014 г. Апатиты. В 3 ч. Ч. 1. Институт проблем промышленной экологии Севера КНЦ РАН. Апатиты: КНЦ РАН, 2014. С. 151-155.

\section{References}

1. Skrypnikova E.B. Osobennosti ekologii bol'shoy sinitsy kak fonovogo vida ornitokompleksov g. Voronezha [Features of the ecology of the Great Tit as a background species of the Ornithocomplexes of the city of Voronezh]. Sovremennye problemy nauki i obrazovaniya [Modern problems of science and education]. 2011. № 5. https://www.science-education.ru/en/article/view?id=4821

2. Lebedeva N.V. Ptitsy-duplognezdniki kak model'nye ob"ekty bioindikatsii [Birds-hollows as model objects of bioindication]. Ptitsy-duplognezdniki kak model'nye obekty $v$ reshenii problem populyatsionnoy ekologii i evolyutsii: materialy mezhdunarodnoy konferentsi [Birds-hollows as model objects in solving problems of population ecology and evolution: materials of the international conference]. M .: The number of scientific publications KMK, 2014, pp. 167-170. 
3. Investitsionnyy pasport goroda Monchegorska [Investment passport of the city of Monchegorsk], 2013. http://minec.gov-murman.ru/files/invest_monch.pdf.

4. Monitoring of the state of the natural environment of the Lapland State Natural Biosphere Reserve, as well as the territory adjacent to Severonickel, including Monchegorsk and its environs (the fifth stage): report on the contract with the Kola Mining and Metallurgical Company No. D-1089 / ed. V.Sh. Barkan. Monchegorsk, 2002. 134 p. Archive of the Lapland Reserve.

5. Berlina N.G. Sosudistye rasteniya Laplandskogo zapovednika (annotirovannyy spisok vidov) [Vascular Plants of the Lapland Reserve (Annotated List of Species)]. Flora i fauna zapovednikov [Flora and Fauna of Reserves]. Issue 64. M., 1997. 58 p.

6. Kataev G.D. Mlekopitayushchie. Fauna Laplandskogo zapovednika [Mammals. Fauna of the Lapland Reserve]. Flora i fauna zapovednikov [Flora and Fauna of Reserves]. Issue. 63. M., 1997, pp. 39-44.

7. Shubina Yu.E., Federyakina I.A., Lykov E.L. Razmery, massa i stroitel'nyy material gnezd chernogo drozda (Turdus Merula (Aves) v Lipetskoy i Kaliningradskoy oblastyakh [Dimensions, mass and building material of the nests of the blackbird (Turdus Merula (Aves) in the Lipetsk and Kaliningrad Regions)]. Bulletin of the Moscow Island of Naturalists, 2011. 2011. V. 116. Issue 6, pp. 48-53.

8. Molokanova Yu.P. Osobennosti ekologii gnezdovaniya penochek (Phylloscops) v Moskovskoy oblasti [Peculiarities of the Ecology of Nesting of Phylloscops in the Moscow Region]. Bulletin of MGOU. 2013. № 1, pp. 1-22.

9. Artemev A.V. Populyatsionnaya ekologiya bol'shoy sinitsy Parus major v taezhnykh lesakh Karelii. Ch. 1. Struktura naseleniya i osobennosti gnezdovaniya [Population ecology of the large titmouse Parus major in the taiga forests of Karelia. Part 1. The structure of the population and the features of nesting]. Uchenye zapiski Petrozavodskogo gosudarstvennogo universiteta [Scientific notes Petrozavodsk State University]. 2008. № 2 (92), pp. 31-43.

10. Zimin V.B. Materialy po gnezdovaniyu bol'shoy sinitsy (Parus Major L.) v Karelii [Materials on the nesting of the Great Tit (Parus Major L.) in Karelia]. Fauna i ekologiya ptits i mlekopitayushchikh taezhnogo Severo-Zapada SSSR [Fauna and ecology of birds and mammals of the taiga Northwest of the USSR]. Petrozavodsk, 1978, pp. 17-31.

11. Blagosklonov K.N. Gnezdovanie i privlechenie ptits $v$ sady i parki [Nesting and attracting birds to the gardens and parks]. Moscow: Izd-vo MGU, 1991. $251 \mathrm{p}$.

12. Bianki V.V., Shutova E.V. K ekologii bol'shoy sinitsy Parus major v Murmanskoy oblasti [To the ecology of the big titmouse Parus major in the Murmansk region]. Russkiy ornitologicheskiy zhurnal [Russian ornithological journal]. 2011. Volume 20. № 628, pp. 186-195. 
13. Kataev G.D. Monitoringovye issledovaniya fauny melkikh mlekopitayushchikh Micromammalia na Kol'skom poluostrove (Laplandskiy zapovednik) [Monitoring studies of the fauna of small mammals Micromammalia on the Kola Peninsula (Lapland Reserve)]. Ekologicheskie problemy severnykh regionov i puti ikh resheniya: materialy $V$ Vserossiyskoy nauchn. konf. s mezhdunar. uchastiem 23-27 iyunya 2014 g. Apatity. V 3 ch. Ch. 1. Institut problem promyshlennoy ekologii Severa KNTS RAN [Ecological Problems of the Northern Regions and Ways to Solve them: Materials of the V All-Russian Scientific Conference. Conf. with intern. Participation June 23-27, 2014 Apatity. At 3 o'clock Part 1. Institute of Problems of Industrial Ecology of the North KSC RAS]. Apatity: KSC RAS, 2014, pp. 151-155.

\section{ДАННЫЕ ОБ АВТОРЕ}

Корякина Татьяна Николаевна, аспирант

Мурманский государственный технический университет ул. Спортивная, 13, г. Мурманск, 183010, Российская Федерация o_umi@list.ru

\section{DATA ABOUT THE AUTHOR}

Koryakina Tatyana Nikolaevna, Graduate Student

Murmansk State Technical University

13, Sportivnaya Str., Murmansk, 183010, Russian Federation

o_umi@list.ru 